\title{
Diabetes Distress among Patients with Type II Diabetes in Alexandria
}

\author{
Hanan Hosni El Sherbini, Lecturer \\ Community Health Nursing, Faculty of Nursing, Alexandria University \\ Rasha Abd El Hakim Abdou, Lecturer \\ Community Health Nursing, Faculty of Nursing, Alexandria University
}

\begin{abstract}
Diabetes mellitus is being increasingly recognized as a serious global health problem and is frequently associated with co-morbid distress contributing double burden for the individual and the society. Objective: Assess diabetes distress among patients with type II diabetes in Alexandria. Setting: The study was carried out at four health care settings rendering services in Alexandria namely: El Ramad Hospital Outpatient Diabetic Clinic, Bacus Family Health Center, Outpatient Diabetic Clinic in the Main University Hospital and Smouha Outpatient Diabetic Clinic. Subjects: Using the equal allocation method a random sample of 90 diabetic patients selected from each of the previously mentioned settings in Alexandria. The total sample size was 360 diabetic patients. Tools: Three tools were used for data collection: Patients' socio-demographic and clinical data structured interview schedule; The Diabetic Distress Scale-17 (DDS-17) and Summary of the Diabetes Self Care Activities Scale (SDSCA). Results: Findings of the present study revealed that less than half (45.6\%) of the patients had high diabetes distress level. Nine variables were found to be predictors of high diabetes distress namely gender, age, residence place, level of education, work status, income sufficiency, disease duration, presence of complications and satisfaction with health services. Conclusion: Diabetes distress is a serious problem among diabetic patients with multiple related risk factors. Recommendations: Routine screening of diabetic patients for depression and diabetes-related distress, empower patients through interactive teaching strategies and involve them in the management of their diabetes.
\end{abstract}

Keywords: Type II diabetes, diabetes distress, diabetic patients.

\section{Introduction}

Diabetes mellitus is one of the most common non communicable diseases globally. It is the fourth or fifth leading cause of death in most high income countries and there is substantial evidence that it is epidemic in many economically developing and newly industrialized countries $^{(1)}$.

Diabetes mellitus is undoubtedly a challenging health problem in the $21^{\text {st }}$ century. Epidemiological evidences suggest that the incidence of diabetes is increasing worldwide. Globally, World Health Organization (WHO) estimated that 382 million people suffer from diabetes with a prevalence of $8.3 \%$. Additionally, the estimated number of diabetic patients in the world is expected to increase from 285 million in 2010 to 439 million in 2030 with a projected increase of $69 \%$ in numbers of adults with diabetes in developing countries and $20 \%$ in developed countries. Moreover, diabetes related deaths will increase by two thirds between 2010 and 2030.The international Diabetes Federation 2014, reported that 387 million people have diabetes and by 2035 this will rise to 592 million. In 2014, Diabetes caused 4.9 million deaths i.e. every seven seconds a person dies from diabetes $^{(2-5)}$. 
In Egypt, Diabetes is on a staggering rise. Data obtained from Egypt Demographic Health Survey (2008) shows that $6 \%$ of adults up to 59 yearsreported that they had diabetes. Recently, the International Diabetes Federation in 2014 estimated thatthere were over 7.5 million cases of diabetes with a prevalence rate reaching $15.4 \%$ among adult aged from 20 to 79 years $^{(6,7)}$.

Type II is the most common form of diabetes mellitus comprising $90 \%$ of people with diabetes around the world. It is also called non-insulin-dependent diabetes mellitus (NIDDM) or adult-onset diabetes. Type II diabetes occurs more frequently in adults than in children sits incidence increases with age, especially after age of 40years ${ }^{(1,2)}$.

Diabetes is the most demanding chronic illness. It poses a big burden on individuals, families and societies ${ }^{(1,8)}$. It challenges every fiber of a patient's body and spirit and demands a system of care that ministers to the biological, social and psychological aspects of the illness ${ }^{(9)}$. Diabetes requires vigilant and sustained adherence to a complex and coordinated treatment regimen and daily management comprising multiple health behaviors to reduce patients' risk of serious complications such as heart disease and stroke, neuropathy and nephropathy ${ }^{(1,8,10)}$. There has been a growing focus on the involvement of patients in their management. Diabetes self-management is crucial to management of the disease and has been shown to mitigate future complications, reduce risk of comorbidities, and improve overall health $^{(11,12)}$

Self-management is an essential element of diabetes care and refers to the individual's ability to manage symptoms, treatment, physical and psychological consequences and lifestyle changes inherent to this chronic condition ${ }^{(13,14)}$. Diabetes management requires long-term adherence to diet, physical activity, medication, and frequent monitoring of blood glucose levels, and patients have to learn to integrate selfmanagement into their daily lives and to cope with complications. However, many patients experience emotional burdens in response to these prolonged requirements and sustaining daily diabetes regimen, including worry about complications, fear of hypoglycemia, feeling of guilt regarding uncontrolled blood glucose, and depressed mood. These negative emotional burdens associated with diabetes are defined as "diabetes-related emotional distress" ${ }^{(8,12,13)}$.

Diabetes-related distress is a part of diabetes and it is a non-psychiatric distress. It refers to the unique, often hidden emotional burdens and worries that are part of the spectrum of patient experience when managing a severe, demanding chronic disease like diabetes. It is a condition where patients are concerned with the management of their diseases, getting the support they need, managing the emotional burden of diabetes, as well as access to needed care $^{(13)}$. It ranges from limited psychological problems to constant diabetes-related selfcare behaviors such as regular blood sugar control, medications administration, insulin injection, and adherence to treatment regime $^{(12-14)}$.

Diabetes-related distress poses additional constraints on patients and health care system. Many studies have revealed that it can significantly affect diabetic patients' health outcomes, especially their self-management ${ }^{(1,14,15)}$.High level of diabetes distress has been associated with poor glycemic control, poor quality of life, poor self-care and low diabetic selfefficacy $^{(14,15)}$. Additionally, people with diabetes distress report more family conflict, have more contact with the healthcare system, and have higher levels of both diabetes complications and death from any cause over time than their counterpart who do not have elevated levels of distress ${ }^{(15,16)}$.

Health care professionals must take necessary steps to better understand the nature of diabetes distress as care that does 
not include recognition and understanding of these aspects of the disease leads to frustration, anger, disappointment, fatigue, disorganization, and burnout for both the clinician and the patient ${ }^{(8,16,17)}$. Unfortunately, the detection rate of diabetes distress, which is important for treatment, is still low. Researchers have identified many relevant factors that can trigger diabetesrelated distress including the diagnosis, signs and symptoms of the diseases, complications, change in life style, cost of treatment and adherence to treatment regimen. Given the importance of a timely diagnosis and treatment of psychosocial distress, screening for diabetes-related distress in patients with diabetes should be integrated in structural diabetes care ${ }^{(18-21)}$.

\section{Aims of the Study}

The aim of the study is to assess diabetes distress among patients with type II diabetes in Alexandria.

\section{Research Question:}

What are types, level and risk factors of diabetes distress among patients with type II diabetes in Alexandria?

\section{Materials and Method}

\section{Materials}

Design: A descriptive design was adopted in this study.

Setting: The study was carried out at four health care settings rendered services for diabetic patients representing the three health sectors in Alexandria namely: El Ramad hospital outpatient diabetic clinic and Baccus family health center (affiliated to Ministry of Health and Population), Outpatient diabetic clinic in the Main University Hospital (affiliated to University Hospitals) and Smouha outpatient diabetic clinic (affiliated to Health Insurance Sector). These clinics were selected because they have the highest attendance rate.

\section{Subjects:}

- The sample size was estimate using Epi info 7 statistical program using the following parameters; prevalence of diabetes distress 26\%, $95 \%$ confidence level with $5 \%$ maximum error. The minimum sample size estimated is 323 patients.

- Using the equal allocation method a random sample of 90 diabetic patients was selected from each of the previously mentioned settings. The total sample size was 360 diabetic patients.

Tools: In order to collect the necessary data for the study three tools were used:

Tool I: Diabetic patients sociodemographic and clinical data structured interview schedule

It was developed by the researcher to collect the necessary data from diabetic patients. It included two parts:

First part: Patients' personal and sociodemographic data: It included the age, sex, level of education, occupation, income, living condition and marital status.

Second part: Patients' health status data: It included data about the disease duration, presence of diabetes complications and follow up.

Tool II: Diabetic Distress Scale -17 (DDS$\underline{17)^{(22)}}$

It is a brief self-reported scale to be used by diabetic patients. It was developed by Polonsky et al at 2005. DDS-17 is used to assess the diabetes related distress reflecting four distinct subscales; emotional burden (5 items), physician related distress (4 items), regimen related distress (5 items) and interpersonal distress (3 items). The responses to each item were rated on a 6 points frequency scale $(1=$ not a problem, $2=\mathrm{a}$ slight problem, $3=\mathrm{a}$ moderate problem, $4=$ somewhat serious problem, $5=$ a serious problem and $6=a$ very serious problem). Considering a mean item score as a level of 
distress worthy of clinical attention, cut off point was selected as little / no distress $<2$, moderate distress $2-2.9$ and high distress $\geq$ 3.

Tool III: Summary of the Diabetes Self Care Activities Scale (SDSCA) ${ }^{(23)}$

It is a self-reporting instrument developed by Toobertet al at 2000 to measure the frequency of performing diabetes self-care tasks. It contains 12 items asked how often several activities such as diet (items1, 2,3), exercise (items 4, 5), medication taking (item 6), blood sugar testing (items 7, 8), and foot care (items 9, $10,11,12$ ) were carried out over a 7-day period. A score of less than three was considered as inadequate, while a score of more than three was considered as adequate (good self-care).

\section{Method}

- Approval from the responsible authorities was obtained through official letters from the Faculty of Nursing.

- Meetings were held with the directors of the selected settings to clarify the purpose of the study and to gain their cooperation and support during data collection.

- Tool (I) was developed by the researcher after reviewing the recent relevant literature. It was validated by juries of (5) experts in the field. Their suggestions and recommendations were taken into consideration.

- Cronbach Alpha Coefficient was used to ascertain the reliability of tool (II) and (III) after translation into Arabic language, $(\mathrm{r}=0.86$ for tool II and 0.82 for tool III).

- Pilot study was carried out on 30 diabetic patients who were randomly chosen from outpatient diabetic clinic not included in the sample namely, "Ras El-Tin Hospital Outpatient Clinic" in order to ascertain the relevance, clarity and applicability of the tools, test wording of the questions and estimate the time required for the interview. Based on the obtained results, the necessary modifications were done.

\section{Ethical considerations:}

- Informed oral consents were obtained from the patients after brief explanation of the purpose and nature of the research.

- Anonymity and confidentiality of responses, voluntary participation and right to refuse to participate in the study were emphasized to patients. The researcher explained the objectives of the study to the participants.

- Data was collected by the researchers during the period from November 2014 to January 2015 (3 months).

\section{Statistical Analysis}

After data were collected, they were coded and transferred into specially designed formats so as to be suitable for computer feeding. Following data entry, checking and verification processes were carried out to avoid any errors during data entry, frequency analysis, cross tabulation and manual revision were all used to detect any errors. The statistical package for social sciences (SPSS version 16) was utilized for both data presentation and statistical analysis of the results. The level of significance selected for this study was $\mathrm{P}$ equal to or less than 0.05 .

\section{Results}

Table (1) shows that less than two thirds $(61.9 \%)$ of the patients were females while the rest $(38.1 \%)$ were males. The age of the patients ranged from 40 to 70 years with a mean of 54.06 \pm 9.54 . More than three quarters $(77.8 \%)$ of the patients were 
married while the rest were single, widowed or divorced. Furthermore, $80.6 \%$ of them were urban dwellers. Concerning the patients' educational level, the table shows that less than one quarter of the patients were illiterate or just could read and write (23.6\%, $19.2 \%$ respectively), while those who completed their basic education, secondary or technical education constituted $20.8 \%$ and $25 \%$ respectively. On the other hand, only $11.4 \%$ of them had university education. The table also portrays that two thirds $(60.6 \%)$ of the patients were not working and $36.7 \%$ of them had a monthly income less than 500 L.E. Moreover, the majority $(91.7 \%)$ of them reported having an insufficient income.

Table (2) reveals that the duration of the disease among patients ranged from less than one year to 14 years with a mean duration of $9.12 \pm 6.58$ years. More than half $(54.2 \%)$ of the patients have a disease duration less than 5 years and the rest reported either 5 to less than 10 years or 10 years or more $(31.4 \%$ and $14.4 \%$ respectively).

Regarding the adequacy of diabetes selfcare management behaviors, less than half of patients reported adequacy with diabetic diet and practicing exercises $(43.3 \%, 34.7 \%$ respectively), while the majority (93.3\%) stated compliance with drug therapy. On the other hand, compliance with foot care and blood sugar testing were reported by $65.6 \%$ and $55.8 \%$ of the patients respectively. The table also portrays that the vast majority (96.1\%) of the patients were performing regular follow up. More than half (61.9\%) of them had at least one follow up visit per month and only11.7\% of them paid three visits or more per month. Lastly, the table shows that less than half $(48.1 \%)$ of the patients reported presence of diabetes related complications and less than one quarter $(23.9 \%)$ of them were satisfied with the health services rendered by the diabetic clinic.

Table (3) presents the distribution of the patients according to the category, level and mean scores of diabetes distress. The table reveals that high diabetes distress level was reported by $45.6 \%$ of the patients and moderate diabetes distress by $39.4 \%$. Only $15 \%$ of the patients had no or low diabetes distress level. Regarding the emotional burden, the table shows that approximately half $(49.4 \%)$ of the patients had high emotional burden level, while $30.3 \%$ and $20.3 \%$ of them had moderate or low level of emotional burden respectively. In relation to the physician distress, less than two thirds (63.3\%) of the patients had high distress while $23.9 \%$ and $12.8 \%$ of them showed either moderate or low level of physician distress respectively. Concerning the regimen distress, the table shows that more than half $(52.8 \%)$ of the patient had high diabetic regimen distress while the rest had either moderate or low regimen related distress $(38.6 \%, 8.6 \%$ respectively).The table also shows that less than half $(48.3 \%)$ of the patients had high degree of interpersonal distress, more than one third (36.1\%) of them had moderate interpersonal distress level and $15.6 \%$ of them show no or low interpersonal related distress level.

Finally, the table reveals that diabetes distress total mean score was $2.31 \pm 0.72$. Physician-related distress was the most common distress encountered among patients $(2.51 \pm 0.71)$, followed by regimen related distress $(2.44 \pm 0.65)$, interpersonal distress $(2.32 \pm 0.73)$ and emotional burden $(2.29 \pm 0.78)$.

Table (4) shows that diabetes distress was more prevalent among female patients $(90.1 \%)$ than males $(76.6 \%)$. A significant relation was observed between the patients' gender and diabetes distress $(\mathrm{P}=0.000)$. Regarding the patients' age, it is evident from the table that the lower the age the higher the diabetes distress since it was more encountered among patients aged forty to less than fifty ( $89 \%$ ) followed by those aged fifty to less than sixty $(83.6 \%)$ however it was least $(81 \%)$ among those aged sixty years and more. Additionally the table reveals that a statistically significant 
relation was found between the patient age and diabetes distress $(\mathrm{P}=0.015)$.Concerning patients' marital status, it is observed from the table that diabetes distress was higher $(86.1 \%)$ among married patients than unmarried ones $(81.3 \%)$. The marital status had a significant impact on patients' distress $(\mathrm{P}=0.052)$. Furthermore, it was observed from the table that diabetes distress was much more encountered among rural residence $(98.6 \%)$ than urban ones $(81.7 \%)$. The place of residence had a significant impact on diabetes distress $(\mathrm{P}=0.002)$. With respect to patients' education, diabetes distress was prevalent among all illiterate patients $(100 \%)$ however; it was least among highly educated patients (78\%). A statistically significant relation was observed between patients' educational level and diabetes distress $(\mathrm{P}=0.000)$. The table also reveals that diabetes distress was more encountered among nonworking patients $(86.7 \%)$ compared to working ones $(82.4 \%)$. A significant relation was detected between diabetes distress and patients' working status $(\mathrm{P}=0.043)$. Lastly, the table illustrates that diabetes distress was higher among patients with monthly family income less than 500 L.E. (90.9\%) and those reported income insufficiency $(86.1 \%)$. Both patients' monthly income and its sufficiency had a significant impact on the occurrence of diabetes distress $(\mathrm{P}=0.000$, $\mathrm{P}=0.001$ respectively).

Table (5) shows the relation between the level of diabetes distress of diabetic patients and their disease experience and self-care management. The table portrays that, the shorter the duration of the diabetes, the higher the level of diabetes distress, since diabetes distress was more encountered among patients who had diabetes for less than 5 years $(98.5 \%)$ compared to $73.1 \%$ of those who had diabetes for more than ten years. A statistically significant relation was found between the disease duration and diabetes distress $(\mathrm{P}=0.000)$. Concerning the adequacy of diabetes self-care management, it is observed from the table that diabetes distress was more prevalent among patients who reported compliance with blood sugar testing $(93.5 \%)$, followed by those patients who reported compliance with diet, medications and foot care $(89.1 \%, 85.1 \%$, $82.2 \%$ respectively).However, it was less encountered among patients who reported compliance with regular exercises $(68.8 \%)$. A Statistically significant relation was observed between adequacy of diabetic selfmanagement and diabetes distress $(\mathrm{P}=0.054)$. The same table also portrays that diabetes distress was higher (92.9\%) among patients who paid no follow up visits and with the same percentage among those with three visits or more. The number of follow up visits had a significant impact on diabetes distress $(\mathrm{P}=0.000)$. Additionally, the table reveals that diabetes distress was more encountered among patients who reported no complications (91.4\%). A statistically significant relation was found between the presence of complications and diabetes distress $(\mathrm{P}=0.000)$. Lastly, the table shows that distress was more prevalent among patients who reported dissatisfaction with health services $(89.1 \%)$. A significant relation was found between the patients' satisfaction with the health services and diabetes distress $(\mathrm{P}=0.000)$.

Table (6) illustrates predictors of diabetes distress among the diabetic patients. The table reveals that nine variables were found to be predictors of high diabetes distress namely gender $(\mathrm{P}=0.003)$, age $(\mathrm{P}=0.000)$, residence place $(\mathrm{P}=0.005)$, level of education $(\mathrm{P}=0.012)$, work status $(\mathrm{P}=0.003)$, income sufficiency $(\mathrm{P}=0.043)$, disease duration $(\mathrm{P}=0.000)$, presence of complications $(\mathrm{P}=0.051)$, and satisfaction with health services $(\mathrm{P}=0.053)$.

\section{Discussion}

Diabetes mellitus is a metabolic disease with a rising prevalence worldwide. It is one of the most common endocrine disorders affecting almost $8.4 \%$ of the world's population ${ }^{(6)}$. Diabetes frequently coexists with mood problems as many people experience considerable distress 
about having diabetes and the amount of hands-on management that it requires ${ }^{(5)}$. This often includes frustration with the ongoing obligations of diet, physical activity, blood glucose monitoring and taking medicines.

Diabetes-related distress refers to significant negative psychological reactions that are specific to one's diabetes diagnosis, potential or actual complications, selfmanagement burdens, difficult patientprovider relationships, and problematic interpersonal relationships ${ }^{(9,11)}$.

It plays an important role in improving diabetes control and regime adherence and is linked to poor behavioural disease management. Identifying and assessing the modifiable determinants of diabetes distress plays a key role in making accurate and appropriate intervention planning programs and should be integrated into patients' selfcare plan to achieve the best possible outcomes $^{(11,13)}$. The aim of the study was to assess diabetes distress among patients with type II diabetic in Alexandria.

Diabetes is a common health problem that permanently changes the person's life either by the demanding set of lifelong selfcare management or by its devastating complications which have an impact on a patient's quality of life ${ }^{(24)}$. The patients may experience high levels of emotional stress stemming from concerns and worries associated with their diabetes and its management. Diabetes specific distress is a common condition that often includes high levels of negative affect ${ }^{(25)}$. Results of the current study portrays that $39.4 \%, 45.6 \%$ of the patients had high and moderate distress respectively (table 3 ). These percentages were dramatically higher than those reported by Fisher et al. at 2009 whofound a prevalence rate of $18 \%$ of distress among patients with Type 2 diabetes ${ }^{(13)}$. Additionally, the proportion of diabetes distress in the current study was much higher than those reported by Islam et al who found that $26.1 \%$ of the diabetic patients in their sample had moderate distress and $22.4 \%$ had high distress ${ }^{(26)}$. However, these results come in line with that of Mullanet al at 2007who found a high prevalence of diabetes distress among T2DM in their longitudinal study for predicting diabetes distress over a period of 18 months as $48 \%$ of participants experienced high levels of diabetes distress ${ }^{(27)}$.Similar results were provided by Baradaran et al at 2014and Sakhar et al at 2013 who found that $35 \%$ and $40 \%$ respectively) of their diabetic patients suffered from diabetes distress ${ }^{(28,29)}$.

Thegreaterburden of having diabetes and the amount of hands on management that diabetes requires, often includes frustration with the ongoing obligations of diet, physical activity, blood glucose monitoring, and taking medicines. This was reflected in the present study finding as $49.4 \%$ of the patients had high emotional burden and $52.8 \%$ of the patients had high regimen distress. In agreement, Islam et al 2013 reported that $56.4 \%$ of the diabetic patients in their sample experienced high diabetes related emotional burden, and $46.1 \%$ of them had high regimen distress ${ }^{(26)}$. The present study also revealed that less than two thirds $(63.3 \%)$ of the patients had high physician distress which may be attributed to lack of communication, effective interactions and trustful relation between patients and their health professionals, lack of the emotional support which is necessary to improve their quality of life and lack of empowerment strategies, information and directions on the proper way for managing their diabetes. The same findings were reported by Fisheret al at 2009 and Zhang et al at $2013^{(13,30)}$.

Regarding the diabetes distress mean scores, results of the current study revealed that diabetes distress total mean score among the patients was $2.31 \pm 0.72$. The mean score for each domain such as physician-related distress, regimen related distress, interpersonal distress and emotional burden was $(2.51 \pm 0.71)$, $(2.44 \pm 0.65),(2.32 \pm 0.73)$ and $(2.29 \pm 0.78)$ 
respectively. These mean scores are in line with those reported by Tol et al at $2012^{(31)}$ on studying distress among Iranian diabetic patients since the total mean diabetes distress score was $2.96 \pm 0.83$. The average score for each domain such as emotional burden, physician-related distress, regimen related distress and interpersonal distress was $(2.40 \pm 1.18),(2.57 \pm 0.88),(2.97 \pm 0.90)$, $(2.76 \pm 0.91)$ respectively. Although, Shojaeezadeh et al at $2012^{(32)}$ reported approach average scores regarding total diabetes distress $(2.17 \pm 0.75)$, lower average scores reported by themregarding domains such as physician-related distress and interpersonal distress $(1.13 \pm 0.32,1.40 \pm 0.65$ respectively).

It has been recognized that diabetes distress is a multi-factorial problem, considering these factors, tailoring a patientcentred, collaborative approach to match the fundamental realities of diabetes care becomes a necessity ${ }^{(22,33,34)}$.Findings drawn from the current study shed light on a set of patient-related variables that were significantly correlates with diabetes distress among patients.

Regarding the patients' sex, results of the present study revealed that distress was significantly higher among female patients than male ones (table 4). In agreement, Islam et al at 2013 and Baradaran et al at 2014 reported that diabetes distress was much higher in female patients ${ }^{(26,28)}$. These findings may be attributed to the fact that the majority of women as housewives spend most of their time at home; they have enough time to think about their diabetes, its complications and how to deal with it. Therefore, they would be overwhelmed and occupied with diabetes related thoughts.

Concerning the patients' age, evidence drawn from the current study significantly indicated that the lower the age of the patients, the higher the level of diabetes distress (table 4). Plausible explanation for such relation may be attributed to the additional stressors posed by managing diabetes on younger people having the life stressors of family responsibilities, work and financial challenges. Moreover, they may cope less effectively with their restricting developmentally unexpected condition. Similar findings were reported by several researchers ${ }^{(3,4,11,20,25,30)}$.

These findings suggest that younger patients may require particular clinical attention to reduce distress and its negative impact on diabetes outcomes.

In line with the developmentalcontextual model of couples coping with chronic illness which emphasizes the dyadic nature of disease management in the context of marriage ${ }^{(35)}$, the results of the current study revealed that diabetes distress was much higher among married patients than unmarried ones (table 4) .Moreover, the study showed significant association between diabetes distress and patients' marital status. The reason behind such significant link could be attributed to the strains and difficulties the married patients face for balancing their diabetes management activities with their family responsibilities and roles. Furthermore, it reflects the struggles they may experience in order to normalize their personal life and counteracting the limiting influence of diabetes on their marital life. These findings were supported by Sakhar et al at 2013 who reported higher diabetes distress level among married patients compared to unmarried ones $^{(29,35)}$.

Regarding the place of residence, the present study revealed that diabetes distress was significantly higher among rural dwellers than urban ones (table 4). These findings could be attributes to the problems of rural areas like inadequate and unsatisfactory health services and the prevalence of illiteracy and poverty which in turn affect the patients' health. In contrast, Fisher et al at $2009^{(13)}$ found that diabetic patients from rural areas had less distress compared to residence of urban areas. 
Considering the patients' education, the present work findings claimed that patients with lower level of education had higher rates of distress. This might be justified that lower level of education and limited literacy hindering patients from access to selfmanagement related information. Along with the same findings, Schillinger et al at 2008 mentioned that the majority of patients presented with diabetes distress were illiterate $^{(36)}$.

It has been anticipated that, the limited financial resources will hinder any person from seeking medical help, getting the expensive treatment and costly diabetes management activities or performing follow up so they face their disease with a more pessimistic view which in return affects their physical and psychological status. This explanation was supported by the findings of the present study since diabetes distress was more encountered among non-working patients and those who reported income insufficiencies. Similarly, Polonsky et al at 2008reported that the cost of diabetes management services was one of the main sources of stress for the diabetic patients ${ }^{(37)}$.

Diabetes is a complex, chronic and costly disease. The quality of diabetes care is widely suboptimal, and most interventions for diabetes depend on active involvement and participation of patients by adhering to prescribed treatment. There has been a great weight of evidence indicated that people with diabetes distress report poorer management of their diet, physical activity, oral diabetes drug usage and blood glucose monitoring ${ }^{(38-42)}$. Conversely, evidence of the current study pointed out that diabetes distress was significantly higher among patients reported adequate self-management behavior regarding diet, medications and blood sugar testing (table 5 ). These findings could be explained by the patients' self-responsibility created by their cautious regarding the disease, worries about the complications combined by their anxiety about inappropriate professional management and services since the majority $(89.1 \%)$ of them reported dissatisfaction with services provided in the health settings.

\section{Conclusion}

Based upon the findings of the current study it could be concluded that distress is a significant health problem prevalent among adults with type 2 diabetes mellitus. Multidimensional risk factors were found to be predictors of high diabetes distress namely gender, age, residence place, level of education, work status, income sufficiency, disease duration, presence of complications and satisfaction with health services.

\section{Recommendations}

- Routine screening of patients with diabetes for depression and diabetesrelated distress.

- Referral to appropriate social services, and psychosocial support; and involvement of mental health professions when needed.

- Empower patients through interactive teaching strategies, involving them in the management of their diabetes, proper communication counseling and self-efficacy, emotional and social support

- The care provided must be patientcentered, culturally sensitive, and appropriate for the patient's age, socioeconomic status, and ethnicity.

- Community resources may include accessible and convenient areas for exercise, affordable fresh food, and access to local pharmacists. In addition, telephonic and web-based interventions are showing promise as tools to reduce depression and anxiety among populations with diabetes. 
Table (1): Distribution of diabetic patients according to their personal and socio demographic characteristics.

\begin{tabular}{|c|c|c|}
\hline \multirow[t]{2}{*}{ Item } & \multicolumn{2}{|c|}{$\mathrm{n}=\mathbf{3 6 0}$} \\
\hline & No & $\%$ \\
\hline \multicolumn{3}{|l|}{ Sex } \\
\hline - Male & 137 & 38.1 \\
\hline - Female & 223 & 61.9 \\
\hline \multicolumn{3}{|l|}{ Age } \\
\hline 40- years & 145 & 40.3 \\
\hline 50- years & 110 & 30.5 \\
\hline $60+$ years & 105 & 29.2 \\
\hline$X \pm S D$ & \multicolumn{2}{|c|}{$54.06 \pm 9.54$} \\
\hline \multicolumn{3}{|l|}{ Marital status } \\
\hline - Married & 280 & 77.8 \\
\hline - Not married (single- widowed- divorced) & 80 & 22.2 \\
\hline \multicolumn{3}{|l|}{ Residence place } \\
\hline - Urban & 290 & 80.6 \\
\hline - Rural & 70 & 19.4 \\
\hline \multicolumn{3}{|l|}{ Educational level } \\
\hline - Illiterate & 85 & 23.6 \\
\hline - Read and write & 69 & 19.2 \\
\hline - Completed basic education (primary + preparatory) & 75 & 20.8 \\
\hline - Completed secondary/ technical education & 90 & 25.0 \\
\hline - Completed university education or more & 41 & 11.4 \\
\hline \multicolumn{3}{|l|}{ Work status } \\
\hline - Working & 142 & 39.4 \\
\hline - Not working & 218 & 60.6 \\
\hline \multicolumn{3}{|l|}{ Monthly income } \\
\hline - Less than $500 \mathrm{LE}$ & 132 & 36.7 \\
\hline - More than $500 \mathrm{LE}$ & 228 & 63.3 \\
\hline \multicolumn{3}{|l|}{ Income sufficiency } \\
\hline - Yes & 30 & 8.3 \\
\hline - No & 330 & 91.7 \\
\hline
\end{tabular}


Table (2): Distribution of diabetic patients according to the disease experience and management.

\begin{tabular}{|c|c|c|}
\hline \multirow[t]{2}{*}{ Item } & \multicolumn{2}{|c|}{$n=360$} \\
\hline & No & $\%$ \\
\hline \multicolumn{3}{|c|}{ Disease duration (in years) } \\
\hline$-\downarrow 5$ & 195 & 54.2 \\
\hline$-5-10$ & 113 & 31.4 \\
\hline$-10+$ & 52 & 14.4 \\
\hline $\mathrm{X} \pm \mathrm{SD}$ & \multicolumn{2}{|c|}{$9.12 \pm 6.58$} \\
\hline \multicolumn{3}{|c|}{ Adequacy of diabetes self-care management behavior\# } \\
\hline - Medication & 336 & 93.3 \\
\hline - Foot care & 236 & 65.6 \\
\hline - Blood sugar testing & 201 & 55.8 \\
\hline - Nutrition & 156 & 43.3 \\
\hline - Exercise & 125 & 34.7 \\
\hline \multicolumn{3}{|c|}{ Number follow up visits / month } \\
\hline - No visits & 14 & 3.9 \\
\hline - One & 223 & 61.9 \\
\hline - Two & 81 & 22.5 \\
\hline - Three or more & 42 & 11.7 \\
\hline \multicolumn{3}{|c|}{ Presence of complications } \\
\hline - Yes & 173 & 48.1 \\
\hline - No & 187 & 51.9 \\
\hline \multicolumn{3}{|c|}{ Satisfaction with health services } \\
\hline - Yes & 86 & 23.9 \\
\hline - No & 274 & 76.1 \\
\hline
\end{tabular}

\# More than one answer is allowed

Table (3): Distribution of the patients according to diabetes distress type, level and mean score.

\begin{tabular}{|c|c|c|c|c|c|c|c|}
\hline \multirow[t]{3}{*}{ DDS domains } & \multicolumn{6}{|c|}{ Level of diabetes distress } & \multirow{3}{*}{$\begin{array}{c}\text { DDS Mean } \\
\text { score } \\
\mathrm{X} \pm \text { SD }\end{array}$} \\
\hline & \multicolumn{2}{|c|}{ No/ Low } & \multicolumn{2}{|c|}{ Moderate } & \multicolumn{2}{|c|}{ High } & \\
\hline & No & $\%$ & No & $\%$ & No & $\%$ & \\
\hline - Total DDS score & 54 & 15 & 142 & 39.4 & 164 & 45.6 & $2.31 \pm 0.72$ \\
\hline - Physician distress & 46 & 12.8 & 86 & 23.9 & 228 & 63.3 & $2.51 \pm 0.71$ \\
\hline - Regimen distress & 31 & 8.6 & 139 & 38.6 & 190 & 52.8 & $2.44 \pm 0.65$ \\
\hline - Interpersonal distress & 56 & 15.6 & 130 & 36.1 & 174 & 48.3 & $2.32 \pm 0.73$ \\
\hline - Emotional burden & 73 & 20.3 & 109 & 30.3 & 178 & 49.4 & $2.29 \pm 0.78$ \\
\hline
\end{tabular}


Table (4): The relation between the patients' diabetes distress and their socio demographic characteristics.

\begin{tabular}{|c|c|c|c|c|c|c|}
\hline \multirow[t]{3}{*}{ Item } & \multicolumn{4}{|c|}{ Diabetes Distress Scores } & \multirow[t]{3}{*}{ Total } & \multirow{3}{*}{$\begin{array}{c}\text { Test of } \\
\text { Significance }\end{array}$} \\
\hline & \multicolumn{2}{|c|}{$\begin{array}{l}\text { No Distress } \\
(\mathrm{N}=54)\end{array}$} & \multicolumn{2}{|c|}{$\begin{array}{l}\text { Distress } \\
(\mathrm{N}=306)\end{array}$} & & \\
\hline & No & $\%$ & No & $\%$ & & \\
\hline \multicolumn{7}{|l|}{ Sex } \\
\hline - Male & 32 & 23.4 & 105 & 76.6 & 137 & $X^{2}=37.345$ \\
\hline - Female & 22 & 9.9 & 201 & 90.1 & 223 & $\mathrm{P}=0.000 * *$ \\
\hline \multicolumn{7}{|l|}{ Age (in years) } \\
\hline$-40-$ & 16 & 11.0 & 129 & 89.0 & 145 & $\mathrm{X}_{2}^{2}=13.212$ \\
\hline$-50-$ & 18 & 16.4 & 92 & 83.6 & 110 & $\mathrm{P}=0.015^{* *}$ \\
\hline$-60+$ & 20 & 19.0 & 85 & 81.0 & 105 & \\
\hline \multicolumn{7}{|l|}{ Marital status } \\
\hline - Married & 39 & 13.9 & 241 & 86.1 & 280 & $X^{2}=11.412$ \\
\hline - Not married & 15 & 18.7 & 65 & 81.3 & 80 & $\mathrm{P}=0.052 * *$ \\
\hline \multicolumn{7}{|l|}{ Residence place } \\
\hline - Urban & 53 & 18.3 & 237 & 81.7 & 290 & $\mathrm{X}^{2}=12.634$ \\
\hline - Rural & 1 & 1.4 & 69 & 98.6 & 70 & $\mathrm{P}=0.002 * *$ \\
\hline \multicolumn{7}{|l|}{ Educational level } \\
\hline - Illiterate & & & & & & \\
\hline - Read and write & 12 & 17.4 & $\begin{array}{l}0 J \\
57\end{array}$ & 82.6 & $\begin{array}{l}05 \\
69\end{array}$ & \\
\hline - Basic education & 23 & 30.7 & 52 & 69.3 & 75 & $\mathrm{X}_{4}^{2}=102.42$ \\
\hline - Secondary/technical & 10 & 11.1 & 80 & 88.9 & 90 & $\mathrm{P}=0.000^{* *}$ \\
\hline $\begin{array}{l}\text { education } \\
\text { - University education }\end{array}$ & 9 & 22.0 & 32 & 78.0 & 41 & \\
\hline \multicolumn{7}{|l|}{ Work status } \\
\hline - Working & 25 & 17.6 & 117 & 82.4 & 142 & $\mathrm{X}^{2}=1.651$ \\
\hline - Not working & 29 & 13.3 & 189 & 86.7 & 218 & $\mathrm{P}=0.043 * *$ \\
\hline \multicolumn{7}{|l|}{ Monthly income } \\
\hline - Less than $500 \mathrm{LE}$ & 12 & 9.1 & 120 & 90.9 & 132 & $X^{2}=34.829$ \\
\hline - More than $500 \mathrm{LE}$ & 42 & 18.4 & 186 & 81.6 & 228 & $\mathrm{P}=0.000 * *$ \\
\hline \multicolumn{7}{|l|}{ Income sufficiency } \\
\hline - Yes & 8 & 26.7 & 22 & 73.3 & 30 & $X^{2}=13.934$ \\
\hline - No & 46 & 13.9 & 284 & 86.1 & 330 & $\mathrm{P}=0.001 * *$ \\
\hline
\end{tabular}

** Significant at $\mathrm{P} \leq 0.05$ 
Table (5): The relation between the patients' diabetes distress and their disease experience and management.

\begin{tabular}{|c|c|c|c|c|c|c|}
\hline \multirow[t]{3}{*}{ Item } & \multicolumn{4}{|c|}{ Diabetes Distress } & \multirow[t]{3}{*}{ Total } & \multirow{3}{*}{$\begin{array}{c}\text { Test of } \\
\text { Significance }\end{array}$} \\
\hline & \multicolumn{2}{|c|}{$\begin{array}{c}\text { No Distress } \\
(\mathrm{N}=54)\end{array}$} & \multicolumn{2}{|c|}{$\begin{array}{c}\text { Distress } \\
(\mathrm{N}=306)\end{array}$} & & \\
\hline & No & $\%$ & No & $\%$ & & \\
\hline \multicolumn{7}{|c|}{ Disease duration (in years) } \\
\hline$-\downarrow 5$ & 3 & 1.5 & 192 & 98.5 & 195 & $\mathrm{X}_{2}^{2}=$ \\
\hline$-5-10$ & 37 & 32.7 & 76 & 67.3 & 113 & 121.385 \\
\hline$-10+$ & 14 & 26.9 & 38 & 73.1 & 52 & $\mathrm{P}=0.000 * *$ \\
\hline \multicolumn{7}{|c|}{ Compliance with diabetes self-management activities } \\
\hline - Diet & 17 & 10.9 & 139 & 89.1 & 156 & $X^{2}=7.452$ \\
\hline - Exercise & 39 & 31.2 & 86 & 68.8 & 125 & $\mathrm{P}=0.054 * *$ \\
\hline - Medication & 50 & 14.9 & 286 & 85.1 & 336 & \\
\hline - Foot care & 42 & 17.8 & 194 & 82.2 & 236 & \\
\hline - Blood sugar testing & 13 & 6.5 & 188 & 93.5 & 201 & \\
\hline \multicolumn{7}{|c|}{ Number follow up visits / month } \\
\hline - No visit & 1 & 7.1 & 13 & 92.9 & 14 & $\mathrm{X}_{2}^{2}=113.56$ \\
\hline - One & 43 & 19.3 & 180 & 80.7 & 223 & $\mathrm{P}=0.000 * *$ \\
\hline - Two & 7 & 8.6 & 74 & 91.4 & 81 & \\
\hline - Three or more & 3 & 7.1 & 39 & 92.9 & 42 & \\
\hline \multicolumn{7}{|c|}{ Presence of complications } \\
\hline - Yes & 38 & 22.0 & 135 & 78.0 & 173 & $X^{2}=15.519$ \\
\hline - No & 16 & 8.6 & 171 & 91.4 & 187 & $\mathrm{P}=0.000^{* *}$ \\
\hline \multicolumn{7}{|c|}{ Satisfaction with health services } \\
\hline - Yes & 24 & 27.9 & 62 & 72.1 & 86 & $X^{2}=112.401$ \\
\hline - No & 30 & 10.9 & 244 & 89.1 & 274 & $\mathrm{P}=0.000 * *$ \\
\hline
\end{tabular}

** Significant at $\mathrm{P} \leq 0.05$

Table (6): Predictors of diabetes distress among the study subjects using binary logistic regression analysis (Enter method).

\begin{tabular}{|c|c|c|c|c|}
\hline Characteristics & $\mathbf{B}$ & S.E. & Wald & $\mathbf{P}$ \\
\hline Sex ( male/ female) & .747 & .636 & 1.381 & $.003 *$ \\
\hline Age ( less than 50 years/ more than 50 years) & 1.735 & .148 & 138.106 & $.000 *$ \\
\hline Marital status (married / not married) & .933 & .664 & 1.972 & .160 \\
\hline Residence place (urban/ rural) & 3.011 & 1.060 & 8.064 & $.005^{*}$ \\
\hline Level of education (university education / less education) & -2.232 & .884 & 6.382 & $.012 *$ \\
\hline Work status (working/ not working) & 1.789 & .601 & 8.846 & $.003 *$ \\
\hline Monthly Income (less than $500 \mathrm{LE} /$ more than $500 \mathrm{LE}$ ) & -.519 & .383 & 1.839 & .175 \\
\hline Income sufficiency (enough /not enough) & 1.373 & .679 & 4.096 & $.043 *$ \\
\hline Disease duration (less than 5 years/ more than 5 years) & -3.673 & .903 & 16.546 & $.000 *$ \\
\hline Regularity of follow up (regular/ irregular) & 14.712 & 779.839 & .000 & .998 \\
\hline Number of follow up visit/ month (once/ more) & 18.431 & 816.941 & .000 & .995 \\
\hline Therapeutic plan compliance (yes/ no) & -.137 & .520 & .069 & .792 \\
\hline Complications ( yes/ no) & .760 & .389 & 3.819 & $.051 *$ \\
\hline Satisfaction with health services (yes/ no) & .344 & 3.758 & -.668 & $.053 *$ \\
\hline Constant & -11.012 & 935.462 & 138.106 & .0001 \\
\hline
\end{tabular}

Model X2 = 231.641, P $<0.0001 \quad$ Cox \& Snell R2=.183 *Significant at P = 0.05 


\section{References}

1. Stanhope M, Lancaster T. Public Health Nursing: Population centered health care in the community. 7 thed USA: Mosby Company; 2008.

2. World Health Organization (WHO).Facts and figures about diabetes. Geneva: WHO; 2014. Available at: http://www.who.int/diabetes/en/.

Retrieved on: 26/11/2014.

3. Global status report on noncommunicable diseases 2014. Geneva, World Health Organization, 2012.

4. Shaw J, Sicree R, Zimmet P. Global estimate of the prevalence of diabetes for 2010 and 2030: diabetes research and clinical practice 2010; 87(1): 4-14.

5. International Diabetes Federation (IDF). IFD diabetes atlas $6^{\text {th }}$ ed. 2014. Available at: http://www.idf.org/diabetesatlas/update2014. Retrieved on: 1/12/2014.

6. El-Zanaty F, Way A. Egypt Demographic and Health Survey 2008. Cairo, Egypt: Ministry of Health. ElZanaty and Associates, and Macro International; 2009.

7. International Diabetes Federation (IDF).MENA, Diabetes in Egypt-2014. Available at: http://www.idf.org/membership/mena/E gypt. Retrieved on: 26/11/2014.

8. Touhy T, Jett K. Gerontological Nursing and Healthy Aging. $3^{\text {rd }}$ ed. Canada: Mosby Co; 2010.

9. Hazzard W, Blass P., Ettinger W, Halter B. Principles of geriatric medicine and gerontology. New York: McGraw-Hill. Gonder Co; 2010, 991-1011.

10. Frederick L., Cox D, Ritterband, M. Diabetes and behavioural medicine: The second decade. Journal of Consulting and Clinical Psychology 2002; 70: 611-25.
11. Gonzalez J, Safren S, Cagliero E, Wexler D, Delahanty L, Wittenberg E. Depression, self-care and medication adherence in type 2 diabetes: relationships across the full range of symptom severity. Diabetes care 2007; 30(9): 2222-7.

12. American Association of Diabetes Educators (AADE). Self-Care Behaviors: The Diabetes educator 2008; 34(3):445-9.

13. Fisher L, Mullan J, Skaff M, Glasgow R, Arean P, Hessler D. Predicting diabetes distress in patients with Type 2 diabetes: A longitudinal study. Diabet Med 2009; 26: 622-7.

14. Rubin R, Peyrot M. Psychological issues and treatments for people with diabetes. J Clin Psychol 2001 Apr; 57(4): 457-78.

15. Spenser M, Kieffer E, Sinco B, Palmisano G, Guzman J, James S, et al: Diabetes-specific emotional distress among African American and Hispanics with type 2 diabetes. Health Care for the poor and underserved 2006, 17: 88-105.

16. Whittermore R, Melkus G, Grey M: Metabolic control, Self-management and psychosocial adjustment in women with type 2 diabetes. J Clinical Nursing 2005, 14(2): 195-203.

17. Peyrot M, Rubin R, Lauritzen T, Snoek F, Matthews D, Skovlund S. Psychosocial problems and barriers to improved diabetes management: Result of the cross- National Diabetes Attitude, Wishes and Needs. Diabetes Med 2005; 22(10):1379-85.

18. Ellis J, Hartley C. Nursing in today's world: trends, issues, and management: the nursing profession and the community. $10^{\text {th }}$ ed. Philadelphia: Lippincott Williams\& Wilkins; 2012.

19. Pouwer F, Beekman A, Lubach C, Snoek F. Nurses' recognition and 
registration of depression, anxiety and diabetes-specific emotional problems in outpatients with diabetes mellitus. Patient Educ Couns 2006 Feb; 60(2): 235-40.

20. American Diabetes Association. Standards of medical care in diabetes-2006. Diabetes Care 2006 Jan; 29(1): 4042.

21. IDF Clinical Guidelines Task Force. Global guideline for type 2 diabetes: Recommendations for standard, comprehensive, and minimal care. Diabet. Med 2006; 23: 579-93.

22. Fisher L, Hessler D, Polonsky W, Mullan J. When is diabetes distress clinically meaningful? Establishing cut points for the diabetes distress scale. Diabetes Care 2012; 35: 259-6.

23. Toobert D, Hampson S, Glasgow R. The summary of diabetes self care activities measure. Diabetes care 2000; 23(7): 943-950.

24. Maurer F, Gwin J .Community public health nursing practices: health for families and populations. $3{ }^{\text {rd }}$ ed. St Louis, USA: El Sevier Saunders; 2009.

25. Ashley L, Backé H, Bates M, Charlebois M, Duffley L, Foster B, et al. Public health community health nursing practices in Canada: role and activities. $4^{\text {th }}$ ed. Canadian Public Health Association; 2010.

26. Islam M, Karim M, Habib S, Yesmin K. Diabetes Distress among Type II diabetic patients. International Journal of Medicine and Biomedical Research 2013; 2(2):113-24.

27. Mullan J, Skaff M, Fisher L. Clinical depression versus distress among patients with type 2 diabetes: not just a question of semantics. Diabetes Care 2007; 30: 542-8.
28. Baradaran H, Mirgobani S, Javanbakht A, Yadollahi Z, Khamseh M. Diabetes distress and its relation with depression among patients with type II diabetes in Iran. International journal of preventive medicine 2014; 4(5): 580-4.

29. Sakhar S, Kodali M, Chakravarithy K. Self-care activities, diabetes distress and other factors which affected the glycemic control in a tertiary care teaching hospital in South India. Journal of clinical and diagnostic research May 2013; 7(5): 875-60.

30. Zhang J, Ping C, Hong-xia W. Comparative study of the influence of diabetes distress and depression on treatment adherence in Chinese patients with type 2 diabetes: a cross-sectional survey People's Republic of China 2013; 9: 1298-4.

31. Tol A, Baghbanian A, Sharifirad G, Eslami A, Alhani $\mathrm{F}$ and Mohajeri $\mathrm{M}$. Assessment of diabetic distress and disease related factors in patients with type 2 diabetes in Isfahan. Journal of Diabetes \& Metabolic Disorders 2012; 11:20- 4 .

32. Shojaeezadeh D, Tehrani M, Sharifirad G, Eslami A. Is Assessing Diabetic Distress An Efficient Pathway to Tailor More Effective Intervention Programs? Geneva Health Forum 2012.

33. Skaff M, Mullan J, Arean P, Glasgow R, Masharani U. A longitudinal study of affective and anxiety disorders, depressive affect and diabetes distress in adults with type 2 diabetes. Diabetes Med 2008 Sep; 25(9): 1096-101.

34. Gonzalez J, Delahanty L, Safren S, Meigs J, Grant R. Differentiating symptoms of depression from diabetes specific distress: relationships with selfcare in type 2 diabetes. Diabetologia 2008; 51: 1822-5 
35. Berg C, Upchurch, R. A developmentalcontextual model of couples coping with chronic illness across the adult life span. Psychological Bulletin 2007; 133: 92054.

36. Schillinger D, Grumbach K, Piette J. Association of health literacy with diabetes outcomes. JAMA 2008; 288: 475-82.

37. Polonsky W, Fisher L, Earles J, Dudl, R,LeesJ, Mullan, J, JacksonR. Assessing psychosocial distress in diabetes. Diabetes Care 2005; 28(3): 626 - 31.

38. Minet L, Mohler S, Vach W, Wagner L, Henriksen J: Mediating the effect of selfcare management intervention in type 2 diabetes: A meta-analysis of 47 randomized controlled trials. Patient Education and Counselling 2010, 80(1): 29-40.
39. Funnell M, Brown T, Childs B, Hass L, Hoset G, Jensen B: National Standards for Diabetes Self-Management Education. Diabetes Care 2010; 33(11): 89-96.

40. Ting R, Nan H, Yu M, Kong A, Wong R. Diabetes-related distress and physical and psychological health in Chinese type 2 diabetic patients. Diabetes care 2011; 34: 1094-6.

41. Delahanty L, Grant R, Wittenbergt E, Bosch J, Wexler D, Cagliero E, Meigs J. Association of diabetes-related emotional distress with diabetes treatment in primary care patients with type 2 diabetes. Diabetes medicine 2007; 24: $48-54$.

42. Glasgow R, Toobert D, Gillette C. Psychosocial barriers to diabetes selfmanagement and quality of life. Diabetes Spectrum2001; 14: 33-41. 